\title{
Evolution and Variation of the Yeast (Saccharomyces) Genome
}

\author{
Robert K. Mortimer ${ }^{1}$ \\ Department of Molecular and Cell Biology, University of California, Berkeley, California 94720 USA
}

In this review we describe the role of the yeast Saccharomyces in the development of human societies including the use of this organism in the making of wine, bread, beer, and distilled beverages. We also discuss the tremendous diversity of yeast found in natural (i.e., noninoculated) wine fermentations and the scientific uses of yeast over the past 60 years. In conclusion, we present ideas on the model of "genome renewal" and the use of this model to explain the mode by which yeast has evolved and how diversity can be generated.

Genetic and Molecular Studies of the Yeast Genome In this discussion the term yeast is used rather loosely because there are hundreds of species of yeast. However, we refer to only a few species in this article, Saccharomyces cerevisiae, Saccharomyces carlsbergensis, Saccharomyces bayanus, and Saccharomyces paradoxus, which are used in the making of wine, bread, beer, and distilled beverages. Taxonomically, yeast is defined as a single-cell eukaryotic microorganism that usually divides by budding.

Although humans have used yeast for centuries (see Box 1), the yeast S. cerevisiae has only been studied at the genetic level since the mid 1930s with the pioneering work of Winge (1935). He used as his starting material, strains of Saccharomyces that had been isolated many years before by Hansen (1891). Lindegren, also one of the pioneers of yeast genetics, used a strain, EM93, that had been isolated by Emil Mrak (Mortimer and Johnston 1986). This strain was found on rotting figs in Merced, California, in 1938, and turned out to be heterothallic (i.e., having two types of sterile haploid individuals which are fertile when together). Other strains found on the same figs were homothallic (one haploid phase that produces gametes capable of fusing to create a zygote).

The strains that Winge studied were nearly all homothallic, which required particular skills in the making of crosses. Lindegren was fortunate in being given a heterothallic strain, constructing crosses was very easy, and eventually this led to the development of modern yeast genetics. However, most of the studies of yeast genetics and, subsequently, yeast molecular biology, were carried out on a very few strains, most of which were derived from Lindegren's original strain EM93. Strain S288C, used to sequence the yeast genome, was constructed in the early 1950s (Mortimer et al. 1957; Mortimer and Johnston 1986). It has been estimated that $\geq 85 \%$ of the genome of S288C comes from EM93 (Mortimer and Johnston 1986). It seems

'E-MAIL ygsc305@violet.berkeley.edu; FAX (510) 642-8589. likely that this original diploid strain was also a wine yeast ( $10 \%$ of wine yeast are heterothallic) and was carried to the rotting figs by insects; the yeast $S$. cerevisae does not travel independently through the air.

Genetic research on the brewing yeasts shows that most have extremely low spore viabilities. Other research suggests that some of them may be polyploid or aneuploid (Johnston 1990). These characteristics would contribute to strain stability and this property may have been inadvertently selected by the brewers. In contrast, most wine strains appear to be diploid and have spore viabilities that range from a few percent to $100 \%$. Relatively little genetic work has been done on baking and distilling yeasts.

\section{Isolation and Diversity of Natural Yeast Strains}

In the wine industry, many wineries now inoculate their fermentations with a starter culture. A relatively small number of such starter strains are in general use, and these were isolated originally from natural fermentations (Johnston et al. 2000). It seems likely that these commercial yeast have been removed from the normal evolutionary processes. A significant number of wineries worldwide ( $10 \%$ in California) do not inoculate and their fermentations nevertheless proceed and are carried out predominantly by $S$. cerevisiae. This is called natural fermentation. We believe that the best approach to study yeast evolution and variation is to analyze the yeast strains that are carrying out these natural wine fermentations.

In one study we showed that 28 strains of $S$. cerevisiae that had been isolated from cellars in the Italian region of Emilia Romagna were all distinct from one another (Mortimer et al. 1994). Recently we examined 36 strains: 18 isolated from a vineyard on Mont Alcino in Tuscany and 18 strains isolated from a vineyard in Sicily (Castiglione di Sicilia), using both genetic and molecular techniques (Cavalieri et al. 1998). These strains were characterized by several different molecular approaches as well as genetic analysis. We found that genetic analysis combined with restriction frag- 


\section{Box 1. Yeast and Human Societies}

The English word yeast has cognates in most other languages. In the Romance languages, the current words are levure (French), lievito (Italian), and levadura (Spanish). In German the word is Hefe and in Dutch it is gist. Older German terms are yes (to ferment) and gäscht (ferment or boil). The Greek language has zéein (to boil), zestos (ferment, boil, hot), and zethos (beer). It seems likely that the English word yeast was derived from Scandinavian sources. The medieval English term is zeest or yest, whereas the Danish word was gjœr. Medieval Icelandic was jast as was medieval Swedish. These various terms generally refer to the lifting, frothing, foaming, or bubbly properties that this species confers on the material upon which it is acting. That these cognates exist in most languages is evidence for the long association of this species with man.

The genus and species names, S. cerevisiae, also can be traced to earlier origins. Saccharomyces means sugar mold or fungus and cerevisiae has its origin in the Gaelic word kerevigia and the old French word cervoise. Both these ancient words for cerevisiae mean beer (Meyan 1838).

Yeast has been an important part of human civilization for a very long time. The earliest evidence of wine making has been dated to Neolithic times $\sim 7400-7000$ years ago. The calcium salt of tartaric acid and the resin of the Pistacia (terebinth) tree have been identified in narrow-necked pottery specimens dated to this period (McGovern et al. 1996, 1998). Tartaric acid occurs in large amounts only in grapes, and it was postulated that the Pistacia resin was added as an antibacteria] preservative. This was considered to be strong evidence for the making of wine at these times. It is not known whether the wine made at the Haji Firuz site was made from domesticated or wild grape. The site lies within the ancient and modern distribution zone of wild grapevine, as established by pollen cores from nearby Lake Urmia. The quantity of wine in the "kitchen", 50 liters (14 gallons) if all six jars contained wine and were nearly full, suggests fairly large-scale production and consumption for a household. If the same pattern of usage were established across the whole of the site's Neolithic stratum, only part of which was excavated, it might be concluded that the grapevine had already come into cultivation (McGovern et al. 1997). Chemical evidence for the making of wine and beer at later Sumerian times (4000 to 3000 BC) has also been detailed (Michel et al. 1992; 1993; McGovern et al. 1995). Evidence for the making of beer came through the demonstration of the presence of calcium oxalate and the shape and construction of the vessels. This evidence was found in the village of Godin Tepe in the Zagros mountains in lower Mesopotamia. The cuisine of the Neolithic period included relatively large-scale production of wine, a processed and fermented beverage made from grape juice, as attested by the chemical confirmation of its presence in jars of a Neolithic residence at Hag Fires in northern Saguaros mountains of Iran (McGovern et al. 1997). The making of wine was probably man's first experience with yeast because the process does not require the use of an inoculum of yeast. The concept of yeast as the microorganism that carried out the fermentation, was not developed until 7000 years later with the work of Pasteur (1872) and others. These early people found empirically that it was necessary only to crush the grapes or other fruit and leave the juice (called must) to ferment. The yeast cells were already on the fruit and ready to carry out the fermentation (Mortimer and Polsinelli 1999). Recently, we have shown that DNA isolated from a presumptive wine jug at Abydos (3150 BC) had a sequence that closely matched the sequence of modern yeast S. cerevisiae (Cavalieri et al. 2000).

The yeast $S$. cerevisiae is an essential component of many important human activities including baking, brewing, distilling, and wine making. It also is now used as a model eukaryotic organism in research activities in hundreds of laboratories worldwide. It can grow and function both aerobically and anaerobically (fermentative). Its principal use involves fermentation. In all four industries, specialized strains of $S$. cerevisiae have been selected and are in use and these strains are not readily interchangeable. Wine-making and baking sometimes involve the use of "natural" strains, and it is apparent that such strains, in contrast to the commercial yeast now used in all these industries, are still evolving.

It appears that bread making dates back at least 6000 years, but use of leavening, which required the development of suitable cereal grains with easily removable hulls, gluten, and the introduction of yeast cells, did not appear until around 500 BC (McGee 1984). With the development of agriculture, it was probably found that addition of some of the fermenting wine to dough resulted in a lighter, more pleasant bread. Alternatively, insects may have landed on the dough and inoculated it with yeast. The use of leavening is described in several verses of Exodus in the Bible. It was found empirically that some of the leavened dough could be used as a starter for a new batch of dough. It is likely that, until recently, the yeast used in baking was evolving, with the participation of

ment length polymorphisms (RFLP) using a subtelomeric probe gave maximum discrimination of strains. The 36 strains chosen for this study gave identical responses in a random amplified polymorphic DNA (RAPD) test. When we analyzed these 36 strains by genetics and RFLP, 34 were unique and two appeared to be the same. Such large diversity is expected in naturally evolving populations.

We used genetic analysis to examine 239 isolates of $S$. cerevsiae from 38 natural fermentations carried out at eight different wineries during the 1993 and 1994 California grape harvest seasons. A total of 28 vineyards were involved. Among these 239 strains, the 87 strains described in Table 1 (below) were unusual. They all sporulated at high (>85\%) frequencies, had $~ 100 \%$ spore viability, and the spore clones grew at uniform rates. Nearly all of the strains appeared to be completely homozygous. These strains are distributed widely over northern California vineyards and are also present in Italian vineyards. The strains marked with an asterisk in Table 1 sporulate permissively, that is, they will sporulate on rich media, such as YPD. Sporulation is essential for the "genome renewal" process to function (see below and Fig. 1).

Strains that accumulate sufficient mutational damage are less likely to readily sporulate and will consequently no longer be able to go through the genome renewal process. Such strains become trapped and will 
Box 1. (Continued)

man, because starters were transferred sequentially from one baking to the next. Following the discoveries of Pasteur and the development of microbiological techniques including the concept of "pure culture," specialized strains were introduced into these industries and evolution was partially interrupted.

In addition to wine, other alcoholic beverages were developed quite early. For example, beer is made from malted barley and other cereals and requires the addition of live yeast cells to promote fermentation. Malting, which was practiced in Egypt and Babylon, dates from at least the third millennium BC. The procedure, which involves sprouting cereal seeds, leads to the conversion of starch to fermentable sugars. Katz and Maytag (1991) have recently made beer using an ancient Sumerian recipe. They state that yeast was inoculated into the original fermentations by addition of grapes and raisins. They also may have been introduced to the malt by the addition of some fermenting wine. An alternative explanation is that insects such as bees, wasps, or Drosophila landed on the malted grain and inoculated it with yeast carried on their bodies. Most distilled beverages are also made from malted grains with the fermentation being carried out by the addition of yeast cells. It seems likely that the yeast cells involved in these processes, until recently, were evolving during sequential transfer.

In wine making, the yeast cells are present on the grapes, and later in the fermentation, for only a few weeks in the year. Attempts to find them in the vineyard either a few weeks before or soon after harvest generally have been unsuccessful (Kunkee and Amerine 1970). Recent evidence suggests that the yeast are brought to the vineyard when the grapes are nearly ripe by insects which perhaps transport them from their nests or hives (Stevic 1962; Snowdon and Cliver 1996). We have shown that these insects primarily feed on damaged berries (Mortimer and Polsinelli 1999). These damaged berries along with many intact berries are then crushed and enter the fermentation. Our studies show that the microorganisms on the damaged berries can provide the principal inoculum for natural fermentations and that they also may make significant contributions to inoculated fermentations. Results discussed in a following section show that evolutionary forces may act on the yeast in the hive, in the vineyard or in the fermentation.

Another model of yeast evolution proposes that the yeast cells are present on the cellar walls and equipment and from there enter the fermentation. When the fermentation is complete, it is proposed that they return to the cellar walls in a closed cycle and it has been argued that evolutionary forces operate to make better wine yeast (Martini 1993). This situation may apply in some special circumstances (real cellars and even caves) but it seems unlikely that it functions in a modern winery with stainless steel, and often closed, fermentation tanks and other stainless steel equipment. Many modem wineries even have their fermentation tanks outside so there are no cellars or cellar walls.

A model proposed by Naumov (1996) states that S. cerevisiae cells are found only in association with human activities. According to this model, the yeast exist in the vineyard and enter the fermentation with the grapes. The model also proposes that the yeast may be transported to the cellar or wine-making equipment by insects and thereby get into the fermentation. Subsequently, the yeast are transported back to the vineyard from the cellar by insects. Evidence in support of this model is that $S$. cerevisiae has been found only in areas close to human civilization. Attempts to find this species of yeast in regions remote from human activities have been unsuccessful. Closely related species such as S. paradoxus and S. bayanus are, however, found in these remote regions.

Today the use of starter cultures in brewing, baking, distilling, and wine making are special cases because, originally, the yeast used in these starter cultures came from a wine or other natural fermentation. Usually these starter cultures were chosen for specific purposes and are often selected from hundreds or thousands of natural isolates. One of the objectives of the companies that sell strains of yeast to wineries and bakeries is to keep the strains without change for many years. Brewers and distillers generally propagate their own yeast but again they attempt to keep the same strains without change from year to year. Such strains would not be in the evolutionary pool.

Brewing, baking, and distilling are year-round operations whereas wine-making is seasonal. In the baking and distilling industries, the $S$. cerevisiae used to carry out these processes is killed by heat. In contrast, brewing is a process that yields a product that still contains live yeast cells. And brewers often use a portion of their fermentations to inoculate a new batch of material for making beer. In these operations, the raw material used does not contain S. cerevisiae. In wine making, in contrast, the raw material (grape must) contains S. cerevisiae which can carry out the fermentations (Mortimer and Polsinelli 1999).

continue to accumulate mutations. Many of the other strains not presented in Table 1 probably fall into this category.

One of the main conclusions from these and other studies is that there is a large amount of diversity in natural strains. Such diversity was also seen in other studies that used pulsed-field gel electrophoresis to screen wild yeast strains (Frezier and Dubourdieu 1992; Schütz and Gafner 1994). We have shown that the most efficient way to detect such diversity is through a combination of genetic and molecular approaches.

\section{Heterozygosities Among Natural Strains}

Next we asked whether the strain was homozygous or heterozygous for the traits studied. Of the 239 strains from the 1993 and 1994 crushes that were examined genetically by tetrad analysis, 155 had one or more heterozygosities and 84 appeared to be completely homozygous. This value (65\%) is close to that found from a study of strains isolated from Emilia Romagna (Mortimer et al. 1994). These heterozygosities are summarized in Table 2 .

\section{Phenotypic Analyses of Natural Isolates and Selection by Evolutionary Forces}

In the initial studies of the 1993 and 1994 crushes, we examined the phenotypes of a total of 2318 colonies for the expression of recessive traits. It is very interest- 
A

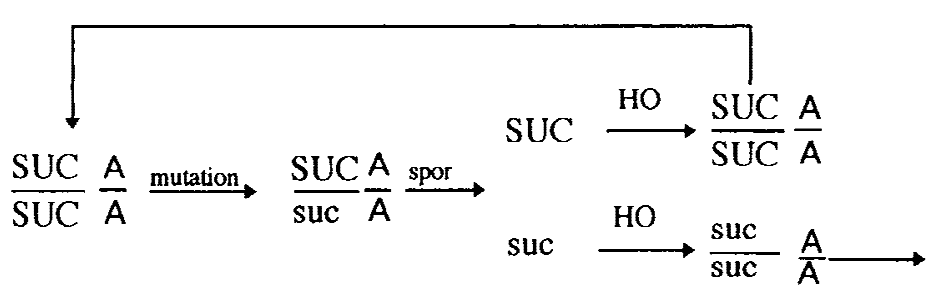

B

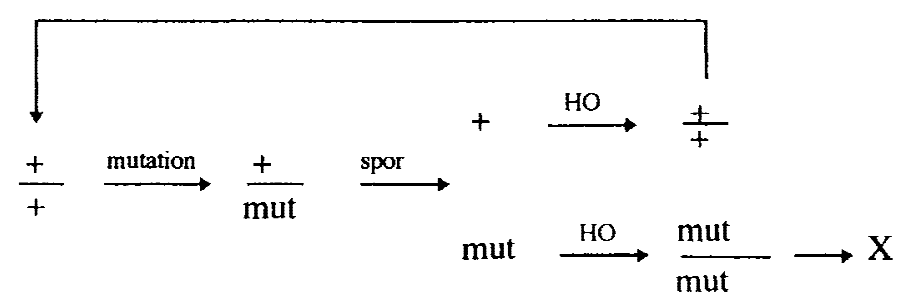

Figure 1 Model of genome renewal. This model applies to wine yeast which are mostly homothallic. Mutations cause recessive heterozygosities which are expressed when the diploid cells sporulate and diploidize through homothallic switching. ( $A$ ). Two loci are considered, SUC and $A$. In the first cycle, one SUC allele mutates to suc, which becomes suc/suc. In the next cycle, $A$ mutates to $a$, which becomes $a / a$. (B). Genome renewal also can eliminate deleterious mutations.

ing to point out that about one half of the traits seen in heterozygous condition are not found in homozygous recessive condition among the natural isolates. Some of the traits that are not found are obvious, but others are not. No auxotrophs were found among these isolates. Also, all 2318 strains were able to grow with glycerol as a carbon source. If such petite (glycerolnegative) strains had occurred, they would have been unable to sporulate and were probably selected against because of their slower growth rates. As expected, lethal mutations were not found in homozygous condition. The mutations that caused the yeast cells to turn yellow on bromothymol blue agar were very pleiotropic and caused slow growth and/or sporulation defects; these mutations were also not found in homozygous condition. Growth rate mutations would also have been selected against. None of the 2318 colonies expressed a colony morphology mutation.

Traits such as sucrose, maltose and galactose fermentation, resistance to copper ion, production of sulfide ion, and homothallism/heterothallism seem to be neutral or at least mild with respect to selection by evolutionary forces. The recessive allele that is expressed as copper sensitivity has a definite selective advantage. One possible explanation is that copper resistance arose several hundred years ago when spraying of vines with copper salts and use of copper containing fermenters and storage vessels was common. Now with government control of these processes, the selective pressure for copper resistance has disappeared. One needs to add that copper resistance involves synthesis of a metallothionein from a complex gene and that in the absence of copper it is to the advantage of the cell to not synthesize this complex molecule.

\section{Genome Renewal as a Mechanism of Evolution of Wine Yeast}

Approximately 69\% of wine yeast is homothallic and most is diploid (Mortimer et al. 1994; Cavalieri et al. 1998). Many such strains will also sporulate permissively, that is, they will sporulate even on a rich medium. Table 1 describes the heterozygosities seen in 239 strains, of which two-thirds is heterozygous. The traits in wine yeast that are in a heterozygous state cover the spectrum of traits seen in the laboratory studies of this yeast. That natural strains are heterozygous for one or more traits is evidence for mutations occurring during the life of this organism. If an $\mathrm{HO} / \mathrm{HO}$ strain has heterozygosities and sporulates, the haploid spores from such a strain will represent all possible combinations of these heterozygosities. $\mathrm{HO}$ is a gene that causes mating type to switch (Herskowiz 1992). Because of the HO gene, some of the descendants of these haploid spores will change mating type, mate, and form diploids. These diploids will be completely homozygous and will compete with each other and with the original diploid. For $n$ heterozygosities, there will be $2 n$ new individuals. It is our view that the $35 \%$ mostly homozygous diploids presented in Table 2 arose by the process of genome renewal from formerly heterozgyous diploids.

Most of these homozygous diploids described in Table 2 are in genotypic classes a and $\mathrm{b}$. The remainder are in the other classes and are homozygous for one or more of the traits scored in the genetic analyses. In these genetic analyses, 10 traits were scored and probably not more than a few hundred genes would control these traits. Thus, members of classes a and, $b$ described in Table 1, could themselves be homozygous for various genes not scored in the genetic analysis; the total number of genes in the $S$. cerevisiae genome is $\sim 6000$. For example, in a recent experiment performed 


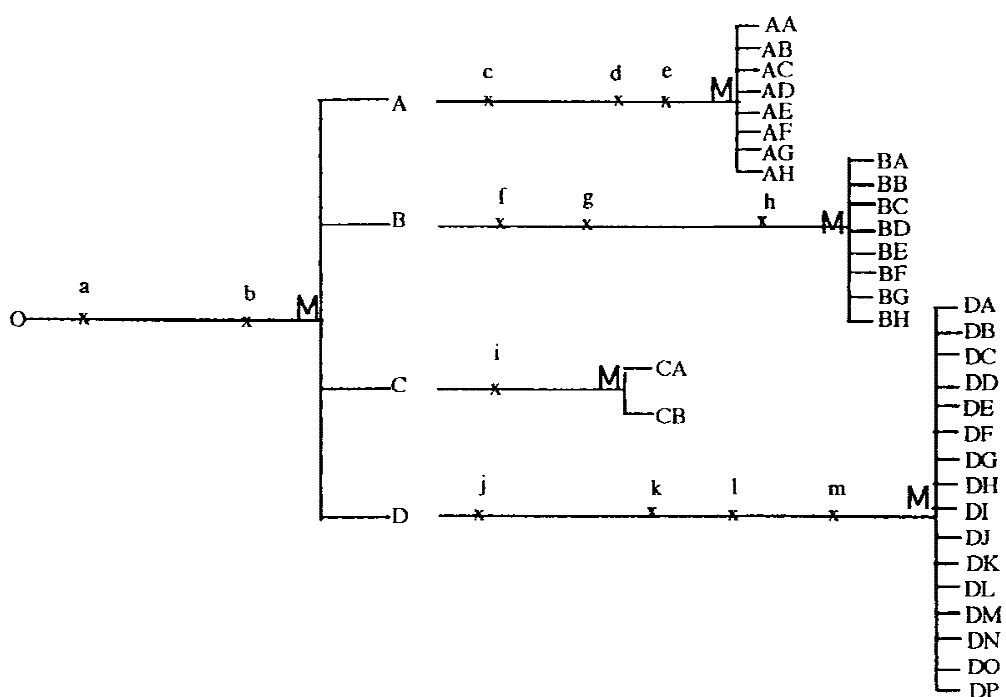

Figure 2 Genome renewal. $a, b, c$, d, etc., represent mutations that occur during mitotic growth; and $M$ represents meioses. In this example, one cell gives rise to 34 individuals during two sporulation-meiosis cycles.

in our laboratory, $10 \mathrm{HO} / \mathrm{HO}$ spore clones were isolated from an apparently homozygous diploid wine strain, S6U. In the genetic analyses, these 10 clones appeared to be identical. These clones were used to make wine using sterile must (juice from crushed grapes containing the yeast), and all 10 fermentations behaved differently with respect to rates of fermentation and foaming properties. In addition, all 10 wines tasted quite different. These wines were also tested for the production of various products of fermentation and were found to vary widely. Glycerol concentrations, for example, varied from 5.1 to 14.6 grams/liter (R.K. Mortimer and C. Baccari, unpubl.). Presumably, these clones were homozygous for various traits affecting fermentation and the flavor of wines but were silent (not expressed) in the genetic analysis. This effect is also illustrated by another example that involves a gene controlling acetoin biosynthesis and degradation. In a survey of 100 strains for the production of higher alcohols and other products of fermentation, 1 strain,
Ba215, was found that produced high levels of acetoin ( $215 \mathrm{mg} /$ liter vs. $\sim 15 \mathrm{mg} /$ liter). Genetic analysis showed that this strain was homozygous for a recessive mutation controlling the biosynthesis of acetoin reductase, an enzyme that converts acetoin into 2,3 butanediol (Romano et al. 1995). This mutation was silent in the normal genetic analysis but was detected by using fermentation procedures combined with genetics. It is our view that this strain arose by genome renewal from a formerly heterozygous strain that in turn arose by spontaneous mutation (Mortimer et al. 1995; P. Romano, G. Suzzi, R. Mortimer, and M. Polsinelli, unpubl.).

The remainder of the strains (65\%) have one or more heterozygosities (Table 2 ), and some of these strains are unable to enter genome renewal either because they are heterothallic or because they have other sporulation defects. It is expected that these strains will continue to accumulate mutations. The balance of the heterozygous strains may enter genome renewal and form homozygous diploids.

\section{Interspecific Hybrids}

Another possible mode of evolution of yeast in the genus Saccharomyces is the formation of interspecific hybrids. Haploid cells or spores of S. cerevisiae, S. bayanus (S. uvarum), and S. paradoxus (S. douglassi) are able to mate with each other and form zygotes that will sporulate. But these zygotes when sporulated are sterile; none of the spores survive. This is presumably because of sequence divergence among the different species that prevents meiotic pairing and recombination. There are also several translocations among $S$. cerevisiae, S. bayanus, and S. paradoxus. Ryu et al. (1996) have constructed hybrids between several of these species and find sterility in all combinations tested. They ar-

Table 1. Classes of Homozygous Variants of Wine Yeast Found Among 239 Strains Isolated During the 1993 and 1994 Crushes

\begin{tabular}{|c|c|c|c|c|c|c|c|c|c|c|c|c|c|}
\hline $\begin{array}{l}\text { Phenotypic } \\
\text { class }\end{array}$ & SUC & MAL & GAL & MIN & COM & CUP & $\mathrm{H}_{2} \mathrm{~S}$ & LET & SPR & $\begin{array}{l}\text { SPR } \\
\text { VBL }\end{array}$ & $\mathrm{HO}$ & $\begin{array}{l}\text { No. } \\
\text { strains }\end{array}$ & $\begin{array}{l}\text { No. } \\
\text { ferm. }\end{array}$ \\
\hline $\mathrm{a}$ & $+/+$ & $+/+$ & $+/+$ & $+/+$ & $+/+$ & $-1-$ & $4 / 4$ & $+/+$ & $\mathrm{H}$ & 100 & $+/+$ & 48 & 21 \\
\hline b & $+/+$ & $+/+$ & $+/+$ & $+/+$ & $+/+$ & $+/+$ & $4 / 4$ & $+/+$ & $\mathrm{H}$ & 100 & $+/+$ & 21 & 11 \\
\hline c & $-1-$ & $+/+$ & $+/+$ & $+1+$ & $+/+$ & $-1-$ & $4 / 4$ & $+/+$ & $\mathrm{H}$ & 100 & $+/+$ & 3 & 3 \\
\hline d & $+/+$ & $-1-$ & $+/+$ & $+/+$ & $+/+$ & $-1-$ & $4 / 4$ & $+/+$ & $\mathrm{H}$ & 100 & $+/+$ & 2 & 2 \\
\hline e & $+/+$ & $-1-$ & $-1-$ & $+1+$ & $+1+$ & $+/+$ & $4 / 4$ & $+/+$ & $\mathrm{H}$ & 100 & $+/+$ & 6 & 5 \\
\hline$f$ & $+/+$ & $+/+$ & $-1-$ & $+1+$ & $+/+$ & $-1-$ & $4 / 4$ & $+1+$ & $\mathrm{H}$ & 100 & $+/+$ & 5 & 4 \\
\hline g & $+/+$ & $+/+$ & $+/+$ & $+1-$ & $+/+$ & $-1-$ & $4 / 4$ & $+/+$ & $\mathrm{H}$ & 100 & $+/+$ & 1 & 1 \\
\hline h & $+/+$ & $+/+$ & $+/+$ & $+/+$ & $+/+$ & $-1-$ & $4 / 4$ & $+1-$ & $\mathrm{H}$ & 50 & $+/+$ & 1 & 1 \\
\hline i & $+/+$ & $+/+$ & $+1-$ & $+/+$ & $+/+$ & $-1-$ & $4 / 4$ & $+/+$ & $\mathrm{H}$ & 100 & $+/+$ & 1 & 1 \\
\hline & & & & & & & & & & & & 84 & 45 \\
\hline
\end{tabular}


gue correctly that sterility of crosses is the only reliable criterion of species distinctions.

There are also reports of another interesting feature of interspecific hybrids. The brewing yeast $S$. carlsbergensis has been shown to be a hybrid of $S$. cerevisiae and some other species, perhaps $S$. monacensis, and also to have changed to a tetraploid (Kiellen-Brandt et al. 1995). This strain was isolated by Hansen in 1908. Some of the chromosomes in this strain are a combination of two different species. The hybrid nature of this strain may be responsible for its popularity as a brewing strain. Two other strains, S6U (Ciolfi 1994) and C1D1, are hybrids of $S$. cerevisiae and S. bayanus. This has been confirmed by molecular evidence. PCR analysis of the met2 gene allows discrimination between these two species. These two strains give patterns characteristic of strains that have the properties of both species. We have carried out a genetic analysis of S6U and have found that it had $\leq 100 \%$ spore viability which was unexpected for an interspecific hybrid. We also found out that the spores of S6U are unable to mate, do not form twin zygotes (Winge 1935), and sporulate to yield sterile spores. We have concluded that this strain is an allotetraploid (C. Baccari, J. Gaine, and R. Mortimer, unpubl.). S. bayanus strains produce $\sim 10$ times the concentration of the aroma compounds $\beta$-phenethyl alcohol and $\beta$-phenethyl acetate in wines as does $S$. cerevisiae and the hybrids produce intermediate concentrations of these compounds (Kishimoto 1994; Sinohara et al. 1994; Masneuf et al. 1998). This is probably one reason that this strain was chosen as a commercial wine strain.

In conclusion, natural wine yeast have tremendous diversity and about two-thirds has one or more heterozygosities. Most wine strains are homothallic and diploid and they evolve rapidly by the process of Genome Renewal.

The publication costs of this article were defrayed in part by payment of page charges. This article must therefore be hereby marked "advertisement" in accordance with 18 USC section 1734 solely to indicate this fact.

\section{REFERENCES}

Cavalieri, D., C. Barberio, E. Casalone, F. Pinzauti, E. Sebastiani, R. Mortimer, and M. Poisinelli. 1988. Genetic and moleuclar diversity in Saccharomyces cerevisiae natural population. Food Technol. Biotechnol. 36: 45-50.

Ciolfi, G. 1994. Selezione di uno stipite di lievito Saccharomyces delia razza fisiologica uvarum e suo impiego enologico allo stato seeco (S6U). L'Enotecnico pp. 71-75.

Frezier, V. and D. Dubourdieu. 1992. Ecology of yeast strain Saccharomyces cerevisiae during spontaneous fermentation in a Bordeaux winery. Am. J. Enology and Viticult. 43: 375-380.

Hansen, E.C. 1891. Undersøgelser over Alkoholgjaersvampenes Fysiologi. Vii. Medd. Carlsberg Lab. 3: 53.

Herskowitz, I. 1992. Mating type determination and mating-type interconversion in Saccharomyces cerevisiae. In The molecular and cellular biology of the yeast Saccharomyces: Gene expression. (ed. E.W. Jones, J.R. Pringle, and J.R. Broach), pp. 583-656. Cold Spring Harbor Laboratory Press, Cold Spring Harbor, New York.

Johnston, J.R. 1990. Brewing and distilling yeasts. In Yeast Technology. (ed. J.F.T. Spencer and D.M. Spencer), pp. 55-104. Springer-Verlag, Berlin, Germany.

Johnston, J.R., C. Baccari, and R.K. Mortimer. 2000. Genotypic characterization of strains of commercial wine yeasts by tetrad analysis. Res. Microbiol. (in press).

Kielien-Brandt, M.C., T. Nillson-Tiligren, C. Gjermansen, S. Holmberg, and B. Pedersem. 1995. Genetics of brewing yeasts. In The yeasts, Vol. 6 (ed. A.H. Rose, A.E. Wheals, and J.S. Harrison), pp. 223-283. Academic Press, London, UK.

Katz, S.H. and F. Maytag. 1991. Brewing and ancient beer. Archaeology pp. 24-31.

Kishimoto, M. 1994. Fermentation characteristies of hybrids between the cryophilic wine yeast Saccharomyces bayanus and the mesophilic wine yeast Saccharomyces cerevisiae. J. Fennen. Bioeng. 77: 432-435.

Kunkee, R.E. and M.A. Amerine. 1970. Yeasts in wine-making. In The yeasts, Vol. 3 (ed. A.H. Rose and J.S. Harrison), pp. 5-81. Academic Press, London, UK.

Martini, A. 1993. Origin and domestication of the wine yeast Saccharomyces cerevisiae. J. Wine Res. 4: 165-176.

Masneuf, I., J. Hansen, C. Groth, J. Piskur, and D. Dubopurdieu. 1998. New hybrids between Saccharomyces sensu scrito yeast species found among wine and cider production strains. Appl. Environ. Microbiol. 64: 3887-3892.

McGee, H. 1984. On food and cooking. Simon and Schuster, New York, NY.

Table 2. Distribution of Homozygous and Heterozygous Segregations Among 239 Strains Isolated from 38 Fermentations

\begin{tabular}{lrrr}
\hline Trait & $+/+$ & $+/-$ & $-/-$ \\
\hline Sucrose fermentation & 231 & 2 & 6 \\
Maltose fermentation & 201 & 22 & 16 \\
Galactose fermentation & 193 & 20 & 26 \\
Growth on minimal medium & 228 & 11 & 0 \\
Growth on glycerol & 210 & 29 & 0 \\
Copper resistance/sensitivity & 43 & 63 & 133 \\
Production of sulfides & 188 & 47 & 4 \\
Homothallism/heterothallism* & 185 & 28 & 26 \\
Yellow/White on BTB & 217 & 22 & 0 \\
Lethal mutations* & 165 & 74 & 0 \\
Growth rate mutations* & 225 & 14 & 0 \\
\hline
\end{tabular}

$\left(^{*}\right)$ Strains that sporulate on rich media.
McGovern, P.E., S.J. Fleming, and S.H. Katz. 1995. The origins and ancient history of wine. Gordon and Breach, Luxembourg.

McGovern, P.E., D.L. Glusker, L.J. Exner, and M.M. Voigt. 1996. Meolithic resinated wines. Nature 381: 480-481.

McGovern, P.E., U. Hartung, V.R. Radler, D.L. Glusker, and L.J. Exner. 1997. The beginnings of winemaking and viniculture in the Ancient Near East and Egypt. Expedition 39: 3-21. prehistory. Archaeology pp. 32-34.
McGovern, P.E. 1998. Wine's 
Meyan, J. 1838. Wiegemann Arch. Naturgeschichte 4: 100.

Michel, R.H., P.H. McGovern, and V.R. Badier. 1992. Chemical evidence of ancient beer. Nature 360: 24 .

Michel, R.H., P.H. McGovern, and V.R. Badler. 1993. The first wine and beer. Anal. Chem. 65: 408A-413A.

Mortimer, R., R. Lerner, and J. Barr. 1957. Ultraviolet-induced biochemical mutants of Saccharomyces cerevisiae. U.S. Afon. Energy. Comm. Doc. UCRL 3746: 1-10.

Mortimer, R. and J. Johnston. 1986. Geneology of principal strains of the Yeast Genetics Stock Center. Genetics 113: 35-43.

Mortimer, R.K., P. Romano, G. Suzzi, and M. Polsinelli. 1994 Genome Renewal: A new phenomenon revealed from a genetic study of 43 strains of Saccharomyces cerevisiae derived from natural fermentation of grape musts. Yeast 10: 1543-1552.

. 1995. Genome renewal: A natural selective mechanism for providing new phenotypes in Saccharomyces cerevisiae. Oenology 95 Fifth International Symposium on Oenology, (ed. A. Lonvaud-Funel), pp. 284-286. Lavoisier Tec DOC, Paris, France.

Mortimer, R. and M. Polsinelli. 1999. On the origins of wine yeast. Res. Microbiol. 150: 199-204.

Naumov, G.I. 1996. Genetic identification of biological species in the Saccharomyces sensu stricto complex. J. Ind. Appl. Microbiol. 17: 295-302.

Naumov, G.I., E.S. Naumova, R.A. Lannitto, E.J. Louis, and M. Korhola. 1992. Genetic homology between Saccharomyces cerevisiae and its sibling species $S$. paradoxius and $S$. bayanus: Electrophoretic karyotypes. Yeast 8: 599-612.

Pasteur, L. 1872. Nouvelles experiences pour démontrer que le germe de la levure qui fait le vin provient de 1'extérieur des grains de raisin. C. R. Searces Acad. Sci. Paris. 75: 781-793.

Romano. P., G. Suzzi, R. Mortimer, and M. Polsinelli. 1995a. Production of high levels of acetoin in Saccharomyces cerevisiae wine yeasts is a recessive trait. J. Appl. Bacteriol. 7: 169-174.

Ryu, S.-L, Y. Murooka, and Y. Kaneko. 1996. Genomic organization between two sibling species, Saccharomyces bayanus and Saccharomyces cerevisiae. Yeast 12: 757-764.

Schutz, M. and J. Gafner. 1994. Dynamics of the yeast strain population during spontaneous alcoholic fermentation determined by CHEF gel electrophoresis. Lett. Appl. Microbiol. 19: 253-257.

Sinohara, T.K., K. Saito, F. Yanagida, and S. Goto. 1994. Selection and hybridization of wine yeasts for improved winemaking properties. J. Fermen. Bioeng. 77: 428-431.

Snowdon, J.A. and D.O. Cliver. 1996. Microorganisms and honey. Int. J. Microbiol. 31: 1-26.

Stevic, S. 1962. The significance of bees (Apis sp.) and wasps (Vespa sp.) as carriers of yeast for the micoflora of grapes and the quality of wine. Arkh. Poljioprivredne Nauke. 50: 80-92.

Winge, O. 1935. On haplophase and diplophase in some Saccharomycetes. C.R. Trav. Lab. Carlsberg Ser. Physiol. 21: 77111. 
Genome Research 10: 403-409 (2000)

Evolution and Variation of the Yeast (Saccharomyces) Genome

Robert K. Mortimer

On page 406, several denotations of Tables 1 and 2 were incorrect. The corrected version is below:

\section{Genome Renewal as a Mechanism of Evolution of Wine Yeast}

Approximately 69\% of wine yeast is homothallic and most is diploid (Mortimer et al. 1994; Cavalieri et al. 1998). Many such strains will also sporulate permissively, that is, they will sporulate even on a rich medium. Table 2 describes the heterozygosities seen in 239 strains, of which two-thirds are heterozygous. The traits in wine yeast that are in a heterozygous state cover the spectrum of traits seen in the laboratory studies of this yeast. That natural strains are heterozygous for one or more traits is evidence for mutations occurring during the life of this organism. If an $\mathrm{HO} / \mathrm{HO}$ strain has heterozygosities and sporulates, the haploid spores from such a strain will represent all possible combinations of these heterozygosities. $\mathrm{HO}$ is a gene that causes mating type to switch (Herskowitz 1992). Because of the $H O$ gene, some of the descendants of these haploid spores will change mating type, mate, and form diploids. These diploids will be completely homozygous and will compete with each other and with the original diploid. For $n$ heterozygosities, there will be $2 n$ new individuals. It is our view that the $35 \%$ mostly homozygous diploids presented in Table 1 arose by the process of genome renewal from formerly heterozygous diploids.

Most of these homozygous diploids described in Table 1 are in genotypic classes a and b. 


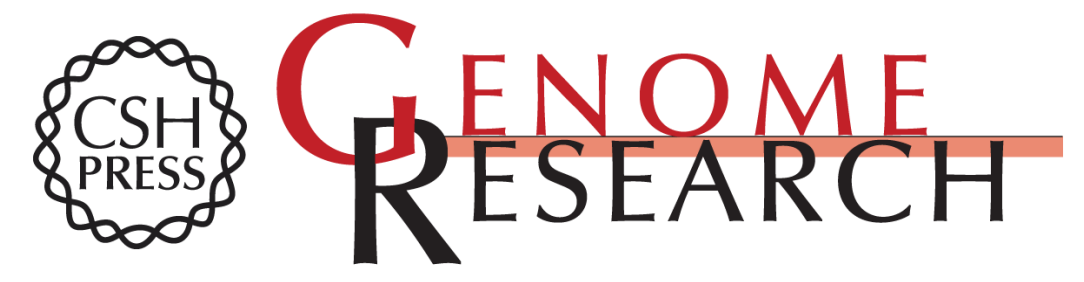

\section{Evolution and Variation of the Yeast (Saccharomyces) Genome}

Robert K. Mortimer

Genome Res. 2000 10: 403-409

Access the most recent version at doi:10.1101/gr.10.4.403

\section{Related Content Genome Res. June, 2000 10: 891}

References This article cites 15 articles, 2 of which can be accessed free at: http://genome.cshlp.org/content/10/4/403.full.html\#ref-list-1

Articles cited in:

http://genome.cshlp.org/content/10/4/403.full.html\#related-urls

\section{License}

Email Alerting

Receive free email alerts when new articles cite this article - sign up in the box at the Service top right corner of the article or click here.

\section{Affordable, Accurate Sequencing.}

